\title{
Perfil epidemiológico de la población desplazada por el conflicto armado interno del país en un barrio de de Cartagena, Colombia, 2000
}

\author{
Diana Carolina Cáceres, Vilma Fabiola Izquierdo, Leonardo Mantilla, Jorge Jara, Martha Velandia \\ Subdirección de Epidemiología y Laboratorio Nacional de Referencia, \\ Instituto Nacional de Salud, Bogotá, D.C., Colombia.
}

Colombia es un país afectado por el desplazamiento como consecuencia del conflicto armado interno; desde 1985 hasta la fecha, se estima que se han desplazado 1'500.000 personas. Con el fin de caracterizar la situación de salud de esta población altamente vulnerable y con tendencia al incremento, se realizó un estudio descriptivo de corte transversal en un barrio de Cartagena entre septiembre y diciembre de 2000. El tamaño de la muestra se calculó para una precisión del $2 \%, 40 \%$ de prevalencia máxima esperada, efecto de diseño de 2 y $15 \%$ de pérdida de información, para un total de 1.600 encuestas de hogar. Se realizó un muestreo monoetápico con reemplazo por conglomerados. A las variables socioeconómicas, ambientales, de morbilidad por grupos de edad y salud metal se les hizo análisis univariado y se determinaron frecuencias, tendencia central y dispersión; análisis bivariado, determinando $\chi^{2}$ o prueba exacta de Fisher y valores de $\mathrm{p}$ y análisis estratificado.

Se encontró deterioro grave en las condiciones socioeconómicas, alta exposición a la violencia, $80 \%$ de las personas entrevistadas refirieron exposición a la violencia antes del desplazamiento y el asesinato fue la causa del $60 \%$ de las muertes reportadas por la comunidad en adolescentes y adultos durante el tiempo de estudio - pero este fenómeno afecta aún a niños menores de 4 años -, disgregación familiar, pésimas condiciones de saneamiento básico, alta prevalencia de enfermedades trazadoras en todos los grupos de edad ( $80 \%$ de los niños menores de 5 años referían síntomas respiratorios, 30\% diarrea y 32\% lesiones purulentas en piel en los 15 días anteriores a la encuesta), deserción escolar (20\% de los escolares y $16 \%$ de los adolescentes), escolaridad tardía, pobre desempeño escolar, proporción importante de niños trabajadores ( $4 \%$ de los escolares y $20 \%$ de los adolescentes), falta de afiliación a la seguridad social (sólo $20 \%$ de los niños menores de 5 años y $50 \%$ de los adultos), poca cobertura y escaso acceso a los servicios de salud, entre muchos otros factores, que pueden actuar sinérgicamente afectando la salud física y mental de la población. Se encontró dificultad para identificar tempranamente a la población desplazada por el conflicto armado interno, especialmente en desplazamientos recientes, familiares o unipersonales, lo que dificulta el apoyo gubernamental. Los resultados indican que es esencial instaurar un sistema de vigilancia con base en líderes comunitarios, que permita aumentar la eficiencia, la eficacia, el acceso y la oportunidad de la atención en salud a la población desplazada.

Palabras clave: desplazamiento. saneamiento básico ambiental, morbilidad, nutrición, salud mental, sistema de vigilancia, líderes comunitarios.

Epidemiological characteristics of a population group displaced by the internal armed conflict in a neighborhood in Cartagena, Colombia, 2000

Colombia faces internal displacement as a consequence of internal armed conflict. From 1985 to the present, it is estimated that $1,500,000$ people have been displaced. A transversal descriptive study aimed at characterizing the health situation of this highly vulnerable and continually growing population was carried out in Cartagena between September and December, 2000 . The sample size was calculated to meet a $2 \%$ precision, $40 \%$ of maximum expected 
prevalence, design effect of 2 and $15 \%$ of information loss, total sample size 1.600 home's interviews. Single-stage sampling with replacement was done by clusters. To socioeconomic, sanitary conditions, morbidity and mental health variables was done univariate analysis, determining frequencies, central trend and dispersion, as well as a bivariate analysis to determine $\mathrm{X} 2$ or Fisher exact test, $\mathrm{p}$ values and stratified analysis.

The study found severe deterioration in socioeconomic conditions, high exposure to violence (80\% was exposed to violence before displacement and murder cause $60 \%$ of deads in teenagers and adults after displacement but even children under 4 years-old was affected by this phenomenon), family disintegration, bad sanitary conditions, high prevalence of tracing diseases in all ages (80\% of under 5 years-old had respiratory syntoms, 30\% diahorrea and $32 \%$ purulent lesions in skin), school desertion (20\% children between 5 and 11 years and $16 \%$ teenagers), late schooling, poor performance at school, high proportion of working children (4\% children between 5 and 11 years and $20 \%$ teenagers), low affiliation to social security systems (only $20 \%$ under 5 years-old children and $50 \%$ adults), low coverage and access to health services, among many other factors whose interaction affects this population's physical and mental health. We found that is difficult to make an early detection of internally displaced populations and thus provide adequate health care when such displacements are recent or involve individual persons. Results show that is essential to implement a surveillance system based on community leaders to increase efficiency, access and opportunity in health care for displaced populations.

Key words: displacement, sanitary conditions, morbidity, nutrition, mental health, surveillance system, community leaders.

No existe suficiente conocimiento a nivel mundial sobre el desplazamiento forzado, problemática que ha sido denominada 'emergencia compleja', en la que se prevé un comportamiento similar al observado en otras situaciones de catástrofe, como son las producidas por terremotos, huracanes o circunstancias similares.

Colombia es un país afectado por el desplazamiento interno de personas como consecuencia del enfrentamiento entre las Fuerzas Armadas, los movimientos guerrilleros y los grupos paramilitares, que han agudizado el conflicto. Este fenómeno se caracteriza por su cronicidad y la dificultad para identificar oportunamente la población objeto de intervenciones, lo cual impide el apoyo social y económico necesario para disminuir su impacto. Se definió como desplazado a "toda persona que se ha visto forzada a migrar dentro del territorio nacional, a abandonar su localidad de residencia y las actividades económicas habituales, porque su vida, su integridad física, su seguridad o libertad

\footnotetext{
Correspondencia:

Diana Carolina Cáceres

dcaceres@ins.gov.co
}

Recibido: 4/09/02; aceptado: 13/12/02 personal han sido vulneradas o se encuentran directamente amenazadas" (1).

El desplazamiento forzado es un fenómeno de importancia para el país, no sólo porque involucra un gran número de personas, sino porque no se esperan -en el futuro próximo- soluciones al conflicto que genera el éxodo masivo. Se desconocen por completo otros efectos que el desplazamiento puede producir sobre la salud de las personas, especialmente en la fase de transición, cuando han estado expuestas durante mayor tiempo a condiciones adversas del medio ambiente 0 a la ausencia de acciones de promoción y prevención, como el estado nutricional, la vacunación, el embarazo en adolescentes y mujeres adultas y el acceso a los servicios de salud, entre otras. Entre los efectos socioeconómicos que produce el desplazamiento forzado, se encuentra el cambio en la actividad laboral y en la composición de la familia y la discriminación y aumento en la proporción de familias con mujeres cabeza de hogar. Igualmente, se estimaba que el $55 \%$ de la población desplazada era menor de 18 años (1-3).

Dependiendo del número de personas el desplazamiento puede ser masivo, familiar o 
individual (1); también se describen las etapas o fases del deplazamiento: urgencia, primeras 72 horas luego del desplazamiento; emergencia, posteriores a las 72 horas y mientras se define un asentamiento temporal, y transición, que va desde la ubicación de la población en un asentamiento temporal, hasta que se logre su reubicación definitiva o retorno al lugar de procedencia (1).

El cálculo estimado de personas desplazadas entre 1985 y 1999 era de 1'485.000, con una tendencia anual ascendente; el porcentaje de municipios afectados oscilaba según las diferentes instituciones entre 12 y $36 \%(1,2)$. En Colombia, hay pocos estudios de morbilidad en comunidades de poblaciones desplazadas. En el estudio realizado por Morales et al. entre 1997 y 1998 (4), en personas desplazadas atendidas en los servicios de consulta externa, urgencias y hospitalización en el departamento de Antioquia, se pudo observar que el mayor porcentaje de consultas ambulatorias se produjo por enfermedades infectocontagiosas como la infección respiratoria aguda (IRA), la enfermedad diarreica aguda (EDA), las enfermedades de la piel y las parasitosis intestinales. En el servicio de urgencias, fueron nuevamente las enfermedades infecciosas (IRA, EDA) las que ocasionaron el mayor número de consultas, si bien a este nivel el trauma jugó un papel importante, con los hombres como los más afectados. La atención del parto, la neumonía y el trauma se encontraron entre las primeras causas de hospitalización. La primera causa de mortalidad fue la neumonía $(25,2 \%)$ y la segunda, las causas perinatales $(18,4 \%)$.

Con el fin de caracterizar la situación de salud de la población desplazada altamente vulnerable y con posible tendencia al incremento en los años venideros y proponer un sistema de vigilancia que permita aumentar la eficiencia, la eficacia, el acceso y la oportunidad de la atención en salud a la población desplazada, como paso esencial para la búsqueda de soluciones integrales y duraderas, se realizó un estudio descriptivo en la población desplazada en fase de transición del barrio Nelson Mandela de Cartagena, Bolívar, cuyo trabajo de campo se llevó a cabo entre el 7 de septiembre y el 5 de diciembre de 2000 .

\section{Materiales y métodos}

Población de estudio: el número estimado de residentes en el barrio Nelson Mandela de Cartagena oscilaba entre 30.000 y 40.000 habitantes, de los cuales entre 15.000 y 20.000 se consideraban desplazados (10.000 residentes de forma permanente y el resto como población flotante). Además, en esta población se encontraban características y representatividad de minorías consideradas como prioridades por el Gobierno y las agencias internacionales, tales como mujeres cabezas de familia, minorías étnicas y menores de 5 años, entre otras.

Diseño y tamaño de muestra: se realizó un estudio descriptivo de corte transversal $(5,6)$. El tamaño de muestra se calculó para una precisión de $2 \%$, una prevalencia máxima esperada para cualquier evento de $40 \%$, un efecto de diseño de 2 y una pérdida del $15 \%$ en la recolección de la información.

El tamaño de la muestra se determinó especialmente teniendo en cuenta a los menores de 5 años, grupo que se estimaba se encontraría en menor proporción en la composición del hogar y que presentaría las mayores prevalencias de algunos problemas objeto de estudio. Dado que los sectores del barrio no eran homogéneos en tamaño y a que era grande la fracción de conglomerados que se incluirían en la muestra elegida teniendo en cuenta el número de hogares necesarios para la realización del estudio ( $\mathrm{n} /$ $\mathrm{N}>0,05$ ), se decidió realizar un muestreo con reemplazo y tomar un gran número de conglomerados para evitar la complejidad del cálculo de la varianza, que incluye el factor de corrección para poblaciones finitas (7).

Se realizó un muestreo monoetápico por conglomerados y se seleccionaron aleatoriamente entre 138 y 152 hogares de cada conglomerado, para un total de 1.600 encuestas de hogar, que se realizaron en 11 conglomerados de los 25 sectores del barrio.

Encuestas de hogar: cada encuesta estuvo constituida por 6 componentes diferentes: 1) condiciones socioeconómicas, demográficas y saneamiento básico ambiental; 2) morbilidad en 
niños menores de 5 años; 3) morbilidad en niños entre 5 y 11 años (escolares); 4) morbilidad en niños entre los 12 y 17 años (adolescentes); 5) morbilidad en personas de 18 años y más, y 6) malud mental en personas mayores de 17 años. El tiempo para la realización de la entrevista de hogar osciló entre 60 y 90 minutos (promedio, 70 $\mathrm{min}$ ). En cada hogar se seleccionó aleatoriamente una persona de cada grupo de edad y se le aplicó la encuesta. El análisis se realizó teniendo en cuenta este mismo esquema. Igualmente, durante el trabajo de campo se les pidió a los encuestadores que recolectaran información sobre las muertes reportadas por la comunidad en todos sectores del barrio (entre agosto y noviembre de 2000, para un total de 7 semanas).

Para evaluar las condiciones de salud mental de la población desplazada se realizaron tres tipos de encuestas se utilizó la clasificación DSM-IV (8): la escala de sintomatología psiquiátrica (9) y las escalas de Zung para depresión y ansiedad, las cuales han sido validadas con anterioridad en otros estudios. Un puntaje superior o igual a 5 en la Escala de Sintomatología Psiquiátrica, se consideró sospechoso de alguna alteración mental. La interpretación de las escalas de Zung para depresión o ansiedad se hizo de acuerdo con la metodología reportada en la literatura.

Dada la extensión del tema, en este artículo sólo presentaremos algunos resultados generales, condiciones de saneamiento básico ambiental y algunas variables seleccionadas por grupos de edad, que consideramos relevantes en la población desplazada. Los resultados completos del análisis por grupos de edad se encuentran disponibles en otras publicaciones.

Exclusiones y reemplazo: cuando las personas de un hogar se rehusaron a participar en el estudio, se tomó la información básica de la encuesta y la fecha de desplazamiento para caracterizar la población. En caso de que la persona que se encontrara en el hogar fuera discapacitada mentalmente o menor de 15 años y no se encontrara acompañada de un adulto o en caso de que la casa se encontrara desocupada luego de tres visitas consecutivas, se reemplazó este hogar por la casa que se encontrara inmediata- mente a la derecha. Las tres visitas consecutivas se realizaron un día entre semana, sábado y domingo.

Métodos de análisis: se realizó análisis univariado y se determinaron frecuencias, tendencia central y dispersión en las variables continuas. Posteriormente se realizó análisis bivariado y se calculó el $\chi^{2}$ o la prueba exacta de Fisher (según la presentación de los datos) y sus valores de p; cuando estaba indicado, se realizó un análisis estratificado para controlar las variables de confusión.

Los datos de nutrición se introdujeron en Epinut, con el fin de comparar la población encuestada con la población de referencia del National Center of Health Statistics (NCHS). Se constituyeron los índices peso/edad, talla/edad y peso/talla. Se utilizó como punto de corte \pm 2 desviaciones estándar (DE) con respecto a los percentiles de estas tablas. Para evaluar el estado nutricional de adultos y adolescentes se utilizó el índice de masa corporal (IMC), siguiendo la metodología internacional. La clasificación y los puntos de corte en adolescentes se hizo de acuerdo al estudio de Rosner et al. (10).

Consentimiento y confidencialidad: a todos los sujetos que entraron al estudio se les informó sobre la naturaleza y los propósitos del mismo; a su vez, el informante dio su consentimiento verbal de aceptación. Los individuos que se rehusaron a participar en el estudio fueron excluidos. La información recolectada fue confidencial y de uso exclusivo del Ministerio de Salud o del Instituto Nacional de Salud con fines de salud pública. Por ser la población desplazada una población en muchas ocasiones amenazada, el nombre de la persona entrevistada y su ubicación se reemplazó por un número consecutivo y de esta forma se registró la información en medio magnético. La realización del estudio contó con la aprobación del comité ético y de investigación del Instituto Nacional de Salud.

\section{Resultados}

Se entrevistaron 1.457 hogares; 41 (2,8\%) rehusaron participar en la encuesta. El porcentaje máximo de participación para cualquiera de los 
sectores del barrio fue de $9,4 \%$ para el sector Las Vegas, uno de los más grandes, y que hizo parte de dos conglomerados durante el trabajo de campo. La pérdida de información para cualquiera de las variables analizadas en las encuestas independientes fue en todos los casos inferior al $10 \%$.

\section{Origen y causas del desplazamiento}

Las personas entrevistadas procedían de 17 departamentos de Colombia y de 207 municipios diferentes. Se observó una mayor proporción de personas procedentes de los departamentos cercanos a la ciudad receptora (Cartagena) y a medida que era mayor la distancia entre el departamento receptor y expulsor, este porcentaje disminuyó (figura 1).

El período de tiempo transcurrido entre el desplazamiento de su lugar de origen y la entrevista a las personas osciló entre 1 mes y 15 años; no se encontró diferencia entre residir en cualquiera de los sectores del barrio y el tiempo de desplazamiento transcurrido $(p>0,05)$. La tendencia en la proporción de personas desplazadas a lo largo de los 15 años fue al ascenso, especialmente a partir de 1999, en los departamentos de Bolívar, Cesar y Chocó $(p<0,05$; figura 2); se encontró tendencia al descenso en otros departamentos (Antioquia, Córdoba, Magdalena y Sucre).

El principal tipo de desplazamiento fue familiar $73,2 \%$ (1.041/1.422); seguido por el unipersonal $17,5 \%(249 / 1.422)$ y masivo $9,3 \%$ (132/1.422). Al comparar 1990 con 2000, se observó estabilidad en la proporción de personas que se desplazaron con su familia, mientras que hubo disminución en la proporción de personas que se desplazaron unipersonalmente y aumento en el desplazamiento masivo; esta diferencia fue estadísticamente

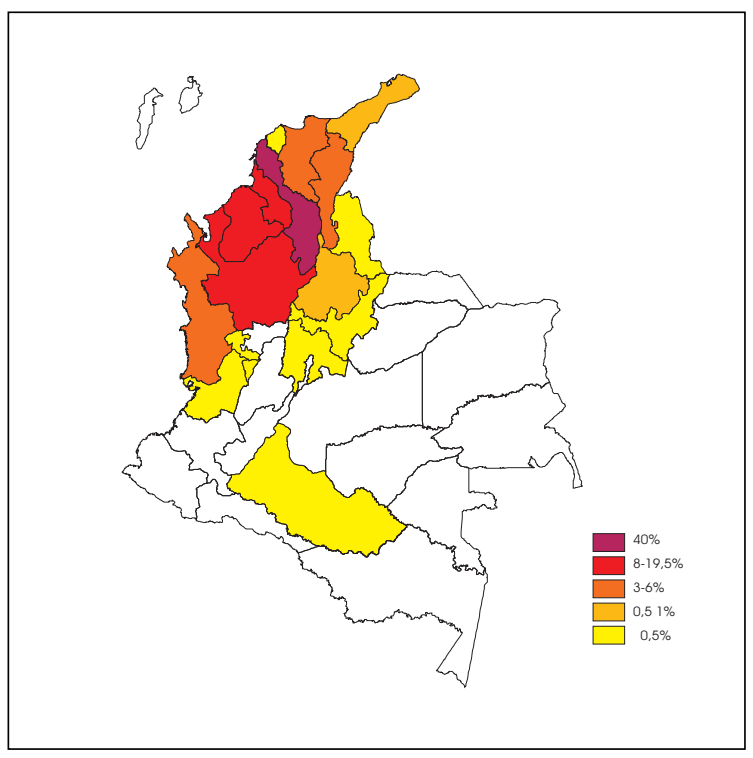

Figura 1. Procedencia por departamentos de las personas afectadas por el desplazamiento interno, Barrio Nelson Mandela, Cartagena, Colombia, 2000.

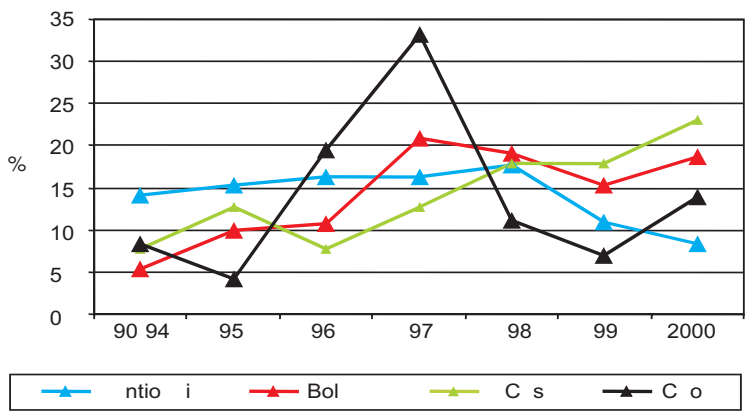

Figura 2. Tendencia por departamento del desplazamiento a través de los años, Barrio Nelson Mandela, Cartagena, 2000.

significativa cuando se compararon los años 1990 a 1996 y 1997 a 2000 (cuadro 1).

La principal razón por la cual los entrevistados salieron de su lugar de origen fue por miedo $(50,5 \%$; 713/1.392). Al comparar años recientes de

Cuadro 1. Distribución del tipo de desplazamiento por fecha de desplazamiento, desde el momento de salida de su lugar de origen a la fecha de la encuesta, Barrio Nelson Mandela, 2000.

\begin{tabular}{lccccc}
\hline \multicolumn{7}{c}{ Desplazamiento } \\
\hline Fecha & unipersonal $\mathbf{n}(\%)$ & $\mathbf{P}$ & familiar $\mathbf{n}(\%)(\mathbf{p}>0,05)$ & masivo $\mathbf{n}(\%)$ & $\mathbf{p}$ \\
\hline $1997-2000(935)$ & $139(14,0)$ & 0,00002 & $690(73,8)$ & $106(12,2)$ & 0,00002 \\
$1990-1996(457)$ & $105(22,9)$ & & $329(72,0)$ & $23(5,1)$ & \\
Total & 247 & & 1024 & 130 & \\
\hline
\end{tabular}


desplazamiento (2000) con años anteriores, se encontró una mayor proporción de personas que refirieron salir por amenazas directas en los años recientes, mientras que para los desplazamientos con fechas más lejanas una mayor proporción de personas salieron de su lugar de origen por miedo $(\mathrm{p}=0,002)$.

\section{Cambio de vida y exposición a la violencia antes y después del desplazamiento}

El 81\% (1.115/1.426) de las personas refirió tener vivienda propia antes del desplazamiento, comparado con el 74\% (1.058/1.431) luego del desplazamiento $(p<0,00001)$; igualmente, antes del desplazamiento sólo $0,6 \%$ (9/1.424) de las personas encuestadas refería tener paredes construidas con material de desecho, mientras que luego del desplazamiento, 29\% (412/1.422) tenían paredes con estos materiales $(p<0,00001)$. Otras variables relacionadas con las características físicas de la vivienda como el material de los pisos, el número de cuartos por vivienda y la disponibilidad de sanitario, entre otras, presentaron una variación similar antes y después del desplazamiento.

En 1.431 hogares entrevistados residían 7.063 personas (rango: 1 a 18 personas), con una media de 5 personas por hogar ( $D E \pm 2,1$ ); $96 \%$ de estos hogares estaban constituidos por una sola familia (rango: 1 a 4 ). Al comparar los desplazamientos ocurridos en el 2000 con los ocurridos en 1996, se observó disminución en la proporción de adolescentes (entre 12 y 17 años) y adultos jóvenes entre los 25 y 34 años $(p<0,04)$ y aumento en la proporción de personas mayores de 60 años $(p=0,06)$.

De los hogares entrevistados, 22,8\% (326/1.429) refirió tener su núcleo familiar completo sin variación antes y después del desplazamiento (incluyendo en este término la familia extensa en los casos en que fuera ésta la composición previa del hogar). El $77,1 \%$ refirió no convivir en el momento de la entrevista con 4.778 personas que formaban parte de su núcleo familiar antes del desplazamiento, lo que equivale en promedio a 3 personas ausentes por hogar entrevistado (rango: 1 a 12 familiares ausentes por hogar).
Estaban ausentes por asesinato, desaparición o secuestro el 10,5\% (491/4.685) de las personas; $86,5 \%(378 / 437)$ de las personas asesinadas o desaparecidas eran de género masculino, con una relación hombre/mujer de 6:1. Debieron salir de Cartagena por amenazas directas 3,39\% (159/ 4.685) de los familiares de los encuestados. Al comparar 1996 con 2000, se observó un aumento significativo $(p<0,005)$ en la proporción de asesinatos (3,7 a 13,5\%), desapariciones ( 0,9 a $5,6 \%$ y amenazas en el lugar actual de residencia $(0,5$ a $4,3 \%)$.

De las personas entrevistadas, $82,3 \%$ (1.170/ 1.421) sufrieron experiencias violentas como asesinato, tortura, secuestro o desaparición de familiares, amigos o conocidos; al analizar esta variable por tiempo de desplazamiento, se observó un mayor porcentaje de personas expuestas a la violencia en los años más recientes de desplazamiento $(p=0,06)$. A pesar de todo lo ocurrido, el $62,9 \%(897 / 1.425)$ de las personas entrevistadas consideraron que el desplazamiento les trajo algún beneficio para su vida; $88,2 \%$ (786/ 884 ) de ellos refirieron la tranquilidad como su principal ganancia.

El 38,9\% (556/1.426) refirió haber recibido ayuda luego de llegar al barrio receptor; esta ayuda fue brindada por familiares, vecinos, amigos o redes comunitarias el 72,8\% (405/556) de las veces; otras fuentes de ayuda fueron: organizaciones no gubernamentales (ONG), 14,3\% (80/556), y organismos gubernamentales, $12,3 \%(68 / 556)$. No se encontró diferencia en la recepción de ayuda y en quienes la brindaron por tiempo de desplazamiento. De las personas encuestadas, el 20\% (285/1.426) recibió algún tipo de ayuda para el mantenimiento del hogar o de los hijos, distribuido de la siguiente forma: dinero, $17 \%$ (47) $278)$; alimentos, 82\% (228/278) y ropa, $1 \%(3 / 278)$. Esta ayuda fue brindada por: familiares, $44,6 \%$ (124/278); gobierno, 35\% (97/278); ONG, 7,2\% (20/ 278), y caridad pública o amigos, 13,2\% (37/278).

La probabilidad de tener ayuda para el mantenimiento del hogar o la familia no mostró diferencias según el tiempo de desplazamiento, pero se encontró aumento en el apoyo de familiares en los desplazamientos recientes y mayor porcentaje de apoyo brindado por 
organizaciones gubernamentales cuando el tiempo de desplazamiento era mayor $(4,3 \%$ en el primer semestre de 2000 y $47,5 \%$ en 1996 ; $\mathrm{p}<0,05)$.

\section{Encuesta de saneamiento básico ambiental}

Se analizaron 1.457 encuestas de hogar. La pérdida de información en cualquiera de las variables estudiadas fue inferior a $4 \%$.

El 43\% (616/1.424) de las viviendas estaban construidas en terrenos de riesgo, ya fuera ondulado o escarpado. Sólo el 1\% (13/1.399) de las personas desplazadas residentes en este barrio refería la presencia de un hospital o puesto de salud cercano a su lugar de residencia.

El 74\% (1.058/1.431) de las personas refería tener vivienda propia, $17,5 \%(248 / 1.431)$ residía en viviendas prestadas y $8,5 \%$ (125/1.431) pagaban arriendo. Las paredes eran de ladrillo o repelladas sólo en el 10\% (143/1.422) de las viviendas; de madera, $61 \%$ (867/1.422) y de material de desecho mixto incluyendo cartón, plástico, material de reciclaje o carpas, $29 \%$. El piso era de tierra en el $82,2 \%$ de las viviendas; de cemento $17,3 \%$ y sólo 0,5\% tenía piso con algún tipo de cobertura.

El promedio de cuartos por vivienda (incluyendo sala-comedor, cocina y baño) fue de 2 habitaciones (rango: 1 a 7). En general, se encontró hacinamiento en la población entrevistada. De los hogares entrevistados, 58,9\% (838/1.424) no tenía cuarto independiente para cocinar; cocinaban en el mismo cuarto donde dormía el 60\% (492/817) y $91 \%(443 / 487)$ de ellos lo hacía con contaminantes ambientales (cocinol, gasolina, leña o gas).

De las viviendas, el 56\% (801/1.431) carecía de servicio de acueducto y obtenía el agua de pila pública $(42,6 \%)$, pozo $(0,2 \%)$ o carrotanque $(12,6 \%)$. Carecía de inodoro, 73,6\% (1.031/1.400) y la disposición de excretas se hacía en pozo séptico (15,6\%; $218 / 1.400)$ o letrina $(10,1 \% ; 142 /$ 1.400). Por el contrario, el $90 \%$ de los encuestados tenía servicio de energía eléctrica.

Refirieron tener servicio de recolección de basuras $27,5 \%$ (392/1.424) de los hogares; este servicio se ofreció una vez por semana en el $93 \%$. Las viviendas que no contaban con este servicio hacían la disposición de desechos de la siguiente forma: cielo abierto, 54\% (545/1.014); relleno, $16 \%$ (163/1.014); incineración, 15,8\% (161/1.014); recolección de la basura por particulares, $11,3 \%$ (115/1.014); el resto las enterraban. Se encontró quema abierta de basuras en $49 \%$ (687/1.419) de los hogares y presencia de lixiviados cerca al lugar de residencia en $34,7 \%(493 / 1.422)$ de las viviendas.

En todos los hogares se informó la presencia de vectores; en $95 \%$ se informó la presencia de ratones y en este mismo porcentaje se informó la presencia de 3 o más vectores, incluyendo zancudos, moscas, pulgas, cucarachas 0 garrapatas.

Al analizar la encuesta de saneamiento básico ambiental por tiempo de desplazamiento, se encontraron las siguientes diferencias: a mayor tiempo de desplazamiento, aumentó la proporción de vivienda propia (44 y 82,2\%, respectivamente) y disminuyó la proporción de viviendas prestadas (31 y 11,9\%, respectivamente, $p<0,000001$ ). De igual forma, a menor tiempo de desplazamiento, mayor cantidad de viviendas tenían paredes de material de desecho $(p<0,05)$.

En cuanto al tratamiento de agua, se observó que a menor tiempo de desplazamiento menor porcentaje de familias trataban el agua, $34,1 \%$ en 1996 y $3,1 \%$ en el primer semestre de 2000 $(p<0,05)$; sin embargo, hervir el agua fue la forma de tratamiento en el $70 \%$ de los hogares, independientemente del tiempo de desplazamiento.

Las demás variables analizadas, incluyendo otras características físicas de la vivienda (piso, energía e inodoro, entre otras), número de personas por hogar, composición del hogar, manejo de basuras, presencia de vectores y otros factores de riesgo, no mostraron diferencias por tiempo de desplazamiento.

\section{Análisis de algunos indicadores de salud seleccionados por grupos de edad}

En el cuadro 2, se muestran las causas muerte en niños y adultos reportadas por la comunidad durante el trabajo de campo. 
Cuadro 2. Mortalidad reportada por la comunidad entre agosto y noviembre de 2000, Barrio Nelson Mandela, Cartagena, 2000.

\begin{tabular}{|c|c|c|c|c|}
\hline Causa & Rango de edad & $\mathbf{n}$ & $\%$ & Observaciones \\
\hline \multicolumn{5}{|c|}{ Mortalidad en niños reportada por los encuestadores } \\
\hline Patología congénita & * & 1 & 6,0 & ${ }^{*}$ Edad desconocida \\
\hline Desnutrición & * & 3 & 18,0 & * Edad desconocida \\
\hline IRA y EDA & $<1$ año & 3 & 18,0 & \\
\hline Tétanos neonatal & Recién nacido & 1 & 6,0 & \\
\hline Accidentes ** & 4 meses * & 2 & 15,0 & $\begin{array}{l}\text { * } 1 \text { niño con edad desconocida } \\
\text { ** Electrocución y asfixia mecánica entre } \\
\text { pared y colchón }\end{array}$ \\
\hline Desconocida & RN a 3 años * & 6 & 37,0 & * Se desconoce la edad de 3 niños \\
\hline Total & & 16 & 37,2 & \\
\hline \multicolumn{5}{|c|}{ Mortalidad en adolescentes y adultos reportada por los encuestadores } \\
\hline Asesinatos $†$ & 15 a 35 * & 22 & 81,4 & $\begin{array}{l}\text { * Se desconoce la edad de } 10 \text { personas } \\
\text { † Incluye } 2 \text { muertes por decapitación }\end{array}$ \\
\hline Aborto provocado & 24 & 1 & 3,8 & \\
\hline Diabetes, infarto e HTA & 33 a 52 años * & 4 & 14,8 & * Se desconoce la edad de 2 personas \\
\hline \multicolumn{2}{|c|}{ Total en adolescentes y adultos } & 27 & 62,8 & \\
\hline
\end{tabular}

* Se desconoce la edad

Cuadro 3. Distribución de género, discapacidad y morbilidad por grupos de edad, Cartagena, 2000.

\begin{tabular}{|c|c|c|c|c|c|}
\hline & $\begin{array}{c}<5 \text { años } \\
(n)\end{array}$ & $\begin{array}{c}5 \text { a } 11 \text { años } \\
\text { (n) }\end{array}$ & $\begin{array}{c}12 \text { a } 17 \text { años } \\
\text { (n) }\end{array}$ & $\begin{array}{l}18 \text { y más años } \\
(n)\end{array}$ & $\boldsymbol{P}$ \\
\hline Género & (788) & (788) & (514) & $(1418)$ & \\
\hline Femenino & 49,4 & 50,3 & 53,3 & 59,9 & $<0,05$ \\
\hline Masculino & 50,6 & 49,7 & 46,7 & 40,1 & \\
\hline Discapacidad & 1,9 & 3,2 & 1,6 & 3,5 & 0,03 \\
\hline Embarazos & & & $\begin{array}{c}(267) \\
7,7\end{array}$ & $\begin{array}{c}(848) \\
12,7\end{array}$ & 0,03 \\
\hline Morbilidad & (782) & (788) & (503) & (1428) & \\
\hline Sano & 7,0 & 20,0 & 39,9 & 33,4 & 0,000001 \\
\hline Síntomas respiratorios & 80,0 & 56,7 & 44,9 & 39,3 & 0,000001 \\
\hline Diarrea & 30,0 & 12,3 & 7,6 & 7,3 & 0,000001 \\
\hline Piodermitis & 32,0 & 34,5 & 19,3 & 12,6 & 0,000001 \\
\hline Accidentes & 2,1 & 2,0 & 2,7 & 1,7 & * \\
\hline $\begin{array}{l}\text { Presencia de lesión en } \\
\text { vagina o pene }\end{array}$ & & & 6,7 & 5,7 & * \\
\hline Secreción uretral o vaginal & & & 13,8 & 20,7 & 0,0005 \\
\hline Enfermedad crónica & & & & 13,2 & \\
\hline
\end{tabular}

* $p>0,05$

Se encontró aumento en la proporción de mujeres con el aumento de la edad. La proporción de personas que se encontraron libres de cualquier sintomatología en los 15 días anteriores a la encuesta fue muy baja y menor a menor edad de la persona entrevistada, llegando a ser de sólo
$7 \%$ en los menores de 5 años, excepto para síntomas sospechosos de enfermedad de transmisión sexual. En estos últimos, la proporción de mujeres que refirió secreción vaginal fue mayor a la proporción de hombres que refirió secreción uretral, 32\% (275/856) y 3,7\% 
Cuadro 4. Atención en salud y promoción y prevención por grupos de edad, Cartagena, 2000.

\begin{tabular}{|c|c|c|c|c|c|}
\hline & $\begin{array}{l}<5 \text { años } \\
(n=799)\end{array}$ & $\begin{array}{c}5 \text { a } 11 \text { años } \\
(n=776)\end{array}$ & $\begin{array}{c}12 \text { a } 17 \text { años } \\
(n=510)\end{array}$ & $18 \underset{(n=1.431)}{\text { y más años }}$ & $\boldsymbol{P}$ \\
\hline \multicolumn{6}{|l|}{ Atención en salud } \\
\hline $\begin{array}{l}\text { Consultó por las enfermedades } \\
\text { en los } 15 \text { días anteriores }\end{array}$ & 29,0 & 13,7 & 12,0 & 17,6 & 0,000000 \\
\hline Hospitalización & 1,4 & 0,5 & 0,4 & 1,2 & * \\
\hline Pagó por la consulta & 52,5 & 40,3 & 41,5 & 50,8 & 0,000000 \\
\hline $\begin{array}{l}\text { No tienen afiliación a Seguridad } \\
\text { Social en Salud }\end{array}$ & 77,9 & 72,0 & 72,5 & 50,8 & 0,000001 \\
\hline $\begin{array}{l}\text { Afiliación a SISBEN } \\
\text { con subsidio en salud }\end{array}$ & 21,2 & 29,0 & 29,5 & 25,2 & 0,0007 \\
\hline \multicolumn{6}{|l|}{ Promoción y prevención } \\
\hline Crecimiento y desarrollo & 13,9 ** & 8,9 ** & & 0,008 & \\
\hline Lactancia materna $>6$ meses & 58,0 & & & & \\
\hline Apoyo nutricional & 31,9 & 9,3 & & & 0,000000 \\
\hline Apoyo nutricional por el ICBF t & $69,0 \dagger$ & $45,0 \dagger$ & & & 0,0002 \\
\hline Asistencia a citología & & & & $64,0 \ddagger$ & \\
\hline Autoexamen de senos & & & & $56,0 \ddagger$ & \\
\hline \multicolumn{6}{|c|}{$\begin{array}{l}{ }^{*} p>0,05 \\
\text { ** número de niños diferente al consignado en la parte superior de la tabla } \\
\text { t ICBF: Instituto Colombiano de Bienestar Familiar } \\
\text { † Incluye sólo el grupo de niños que reciben apoyo nutricional. } \\
\text { † Incluye sólo las mujeres. }\end{array}$} \\
\hline
\end{tabular}

$(21 / 572)$, respectivamente; $p<0,05)$. No se encontró diferencia estadística en el antecedente de enfermedad crónica por género (cuadro 3).

A pesar del número alto de personas que referían síntomas en los 15 días anteriores a la encuesta, la proporción de consultas fue muy baja y fue menor en escolares y adolescentes (cuadro 4). La principal razón para que los menores de 5 años no fueran llevados a valoración médica fue la falta de dinero para pagar la consulta $(60 \%$; $334 / 552)$; $24 \%(132 / 552)$ de las madres no consideraron necesaria la consulta y fue negada la atención a $2 \%$ de los niños. Un comportamiento similar se observó en escolares, adolescentes y adultos, aunque en ellos un porcentaje considerable refirieron como causa para no consultar la falta de afiliación al sistema de salud.

Se observó baja asistencia a los programas de promoción y prevención en todos los grupos de edad, siendo más crítica en los escolares (cuadro 4). Las principales razones por las cuales los niños menores de 5 años no se llevaron a acciones de promoción y prevención, fueron la carencia de dinero, 49\% (235/479), y la carencia de afiliación al sistema de seguridad social, $16,5 \%$
(79/479). Otras razones referidas fueron: lejanía del hospital o puesto de salud; falta de tiempo; no considerarlo necesario; por estar "sano" el niño. Le rechazaron este servicio a $1,8 \%$ de los niños. Un comportamiento similar se observó con la asistencia a programas de promoción y prevención en los demás grupos de edad.

En cuanto a vacunación (verificada con carnet) se observó baja cobertura en menores de 5 años y escolares, tanto para biológicos que requieren tres dosis como para los que requieren una sola dosis; la cobertura de DPT, triple viral, hepatitis B y Hib aumentó significativamente con el aumento de la edad, pero con ningún biológico se alcanzaron coberturas útiles para la prevención de enfermedad (cuadro 5).

La asistencia a actividades de recreación aumentó con la edad de la persona entrevistada, pero fue extremadamente baja en niños y adolescentes (cuadro 6); igualmente, llama la atención que sólo un mínimo porcentaje de la recreación en menores de 17 años fue dirigida por personal capacitado para manejo del trauma ocasionado por la violencia. Debe aclararse que la recreación de las personas mayores de 17 años incluye actividades 
Cuadro 5. Coberturas de vacunación por grupos de edad, Cartagena, 2000.

\begin{tabular}{lccc}
\hline Vacunas & $\begin{array}{c}<5 \text { años } \\
(\mathbf{n = 3 4 5})\end{array}$ & $\begin{array}{c}5 \text { a 11 años } \\
(\mathbf{n = 1 6 1 )}\end{array}$ & $\boldsymbol{p}$ \\
\hline BCG & 85,0 & 86,3 & $*$ \\
$\begin{array}{l}\text { Poliomielitis } \\
\text { Ninguna dosis }\end{array}$ & 7,6 & $3,7^{* *}$ & $*$ \\
3 dosis & 62.2 & $63.8^{* *}$ & $*$ \\
DPT & & & \\
$\quad$ Ninguna dosis & 18,0 & 5,9 & 0,0003 \\
3 dosis & 54.0 & $87.5^{* *}$ & 0.000000 \\
$\begin{array}{l}\text { Triple viral } \\
\text { Hepatitis B }\end{array}$ & 52,3 & 79,5 & 0,000000 \\
$\begin{array}{l}\text { Haemophilus } \\
\text { influenzae }\end{array}$ & 52,0 & 68,3 & 0,0008 \\
Fiebre amarilla & 25,0 & 39,0 & 0,001 \\
\hline
\end{tabular}

\footnotetext{
* $p>0,05$

${ }^{* *}$ número de niños diferente al consignado en la parte superior de la tabla
}

de tipo comunitario, cultural y religioso, que hacen que este porcentaje aumente considerablemente, especialmente a expensas de las actividades religiosas que aumentaron luego del desplazamiento 4 veces en hombres y 2,5 veces en mujeres. Otras variables de interés como el consumo de drogas y alcohol pueden ser observadas en el cuadro 6 .

En cuanto a nutrición, se observó una prevalencia de 23,8\% (IC 95\%: 20,8-27,1) de menores de 5 años con talla por debajo de $2 \mathrm{DE}$, lo que plantea un problema crónico de déficit de ingestión proteico-calórica. De igual manera, 5\% (IC 95\%: $3,9-7,9)$ de los niños en este grupo de edad presentaron valores compatibles con un estado de desnutrición. En escolares, se observó una prevalencia de 13,8\% (IC 95\%: 11,5-16,5) niños con talla por debajo de 2 DE y $3,2 \%$ (IC 95\%: 2,1$4,9)$ se encontraron con valores compatibles con estado de desnutrición.

Al analizar el IMC de los adolescentes por edad y género, se observó un porcentaje muy elevado clasificado en estado de desnutrición, que osciló entre 43 y $81 \%$; igualmente, se observó una mayor proporción de hombres en este estado, que aumentó con el incremento de la edad y que fue estadísticamente significativo a partir de los 15 años. En adultos, el análisis de IMC mostró bajo porcentaje compatible con desnutrición $(1,8 \%)$ y un porcentaje importante clasificado en obesidad $(17,7 \%)$ y obesidad severa $(5,5 \%)$.

En la escala de sintomatología psiquiátrica, el $54,9 \%(783 / 1.425)$ de las personas entrevistadas tuvieron un puntaje superior o igual a 5 (sospechosos de tener alguna alteración mental). En general, se encontró mayor proporción de mujeres con sospecha de alteración mental $(67,6 \% ; 529 / 782)$ y fue este género el que refirió un mayor porcentaje en la mayoría de síntomas explorados que forman parte de esta escala.

En la escala de Zung, 34,7\% (243/700) personas entrevistadas presentaron sospecha de depresión y puntaje compatible con estado depresivo, $23,4 \%$ (164/700). A medida que aumentó la escolaridad fue mayor la proporción de personas con resultados normales en la prueba $(p<0,05)$. Por estado civil, se encontró mayor proporción de personas que presentaron resultados anormales cuando eran viudas $(p<0,05)$, sin diferencia estadística en otros estados civiles. No se encontraron diferencias en

Cuadro 6. Actividades y hábitos por grupos de edad, Cartagena, 2000.

\begin{tabular}{lccccc}
\hline Actividades y hábitos & $\begin{array}{c}\text { Menor } \\
\mathbf{5} \text { años } \\
(\mathbf{n = 8 0 1 )}\end{array}$ & $\begin{array}{c}\mathbf{5} \text { a 11 } \\
\text { años } \\
(\mathbf{n = 7 8 0 )}\end{array}$ & $\begin{array}{c}\mathbf{1 2} \text { a 17 } \\
\text { años } \\
(\mathbf{n = 5 0 5})\end{array}$ & $\begin{array}{c}\mathbf{1 8} \text { y más } \\
\text { años } \\
(\mathbf{n = 1 . 4 2 8})\end{array}$ & $\boldsymbol{p}$ \\
\hline Recreación & 1,5 & 15,1 & 27,2 & 71,0 & 0,000001 \\
Estudio en la actualidad & & 80,7 & 64,0 & 0,000000 \\
Trabajan en la actualidad & 4,2 & 20,8 & 23,8 & 0,000000 \\
Consumo de cigarrillo & & & 1,95 & 0,000000 \\
Consumo de alcohol en & & & 2,0 & 0,000000 \\
el último mes & & 0,2 & 7,0 & 0,0009 \\
Consumo de marihuana & & & 1,9 & 0,005 \\
Consumo de cocaína & & & & \\
\hline
\end{tabular}


el resultado de la prueba cuando se analizó por género o edad; por último, la proporción de personas que presentaron prueba de Zung positiva o sospechosa para depresión o ansiedad no varió por tiempo de desplazamiento.

El modelo de regresión para explicar cambios en la escala de Zung para depresión mostró que las mismas variables que resultaron significativas en el análisis descriptivo fueron significativas en la regresión, excepto el estado civil; se encontró que la unión libre entró a explicar parte del resultado obtenido, además de la viudez; como factor protector ingresó al modelo encontrar algún beneficio con el desplazamiento (cuadro 7). No se observó cambio en la variable dependiente cuando las personas referían exposición a la violencia (haber sufrido experiencias violentas como tortura, secuestro, asesinato o desaparición de familiares, amigos o conocidos), la pérdida de algún familiar por esta causa o deterioro en la calidad de vida. Por último, no se encontró interacción entre ninguna de las variables analizadas. Debe aclararse que se consideró deterioro en la calidad de vida cuando se encontraron cambios en la capacidad adquisitiva o características de la vivienda antes y después del desplazamiento, por ejemplo, haber tenido vivienda propia en el lugar de origen y en el momento de la encuesta residir en vivienda prestada; haber tenido vivienda con piso de baldosa antes del desplazamiento y con piso de tierra luego del mismo.

\section{Análisis de las variables seleccionadas por tiempo de desplazamiento y grupos de edad}

Se encontraron las siguientes diferencias: a mayor tiempo de desplazamiento, aumentó la proporción de niños menores de 5 años con 3 dosis de vacuna (demostradas con carnet de vacunación), para los biológicos que lo requieren así; sin embargo, la aplicación de las 3 dosis de biológicos siguió siendo de forma tardía independiente del tiempo de desplazamiento; se necesitaron dos o más años para alcanzar el número requerido de dosis. Debido al escaso número de niños en este grupo de edad que tenían carnet de vacunación, no se encontraron diferencias significativas por tiempo de desplazamiento en algunos biológicos $(p>0,05)$.
Cuadro 7. Modelo de regresión para las escalas de sintomatología siquiátrica y de Zung para depresión, Cartagena, 2000.

\begin{tabular}{lccc}
\hline Variable & OR & $\boldsymbol{p}$ & IC 95\% \\
\hline \multicolumn{4}{c}{ Escala de Zung para depresión } \\
Edad & 1,00 & 0,726 & $0,98-1,01$ \\
Escolaridad & 0,93 & 0,016 & $0,87-0,98$ \\
Estado civil & & & \\
$\quad$ Unión libre & 1,64 & 0,043 & $1,01-2,65$ \\
$\quad$ Viudo & 2,24 & 0,029 & $1,08-4,64$ \\
Encontrar beneficio & 0,49 & 0,000 & $0,35-0,68$ \\
\hline
\end{tabular}

De igual forma, a menor tiempo de desplazamiento menor proporción de niños menores de 5 años con diarrea, pasando de $27,5 \%$ (30/109) en aquellos niños cuyos padres se habían desplazado en 1996 a 15,7\% (11/70) para los niños que se habían desplazado en el primer semestre del año $2000(p<0,06)$. Un comportamiento similar se observó en la proporción de niños con síntomas respiratorios, que pasó de $67 \%$ (47/70) en el primer semestre de 2000 a $81 \%(88 / 109)$ en 1996 $(p<0,03)$, así como en la proporción de niños menores de 5 años que se encontraron libres de síntomas respiratorios, diarrea o lesiones purulentas en piel que pasó de $11,9 \%$ (13/109) en 1996 a $24,3 \%(17 / 70)$ en el primer semestre de $2000(p<0,05)$.

Otras variables relacionadas con salud y enfermedad como estado nutricional, porcentaje de niños hospitalizados, accidentes, porcentaje de consultas, financiamiento de consultas y drogas, entre otras, no mostraron ninguna diferencia por tiempo de desplazamiento. Por el contrario, la proporción de niños afiliados a seguridad social fue menor a menor tiempo de desplazamiento: en el primer semestre de 2000 este porcentaje fue de $12,9 \%$ (9/70), mientras que para los niños cuyos padres se desplazaron en 1996, este porcentaje se incrementó a 30\% (32/ 108; $p<0,0009$ ). Un comportamiento similar se observó en el porcentaje de niños con Sistema de Identificación de Beneficiarios (Sisben) con subsidio para atención en salud, que fue 2,2 veces mayor en 1996 al comparar con el primer semestre de $2000(p<0,01)$.

El apoyo recibido para dar alimentos adicionales en los menores fue mayor a mayor tiempo de 
desplazamiento (35,8\% en 1996, comparado con $22,9 \%$ en $2000 ; p=0,06$ ). De igual forma, a menor tiempo de desplazamiento mayor porcentaje de niños recibieron ayuda por instituciones no gubernamentales (ONG) y a mayor tiempo de desplazamiento mayor ayuda recibida por el Instituto Colombiano de Bienestar Familiar (ICBF); sin embargo, esta diferencia no fue estadísticamente significativa, aunque pudo ser debido al escaso número de niños encuestados que pertenecían a cada una de las fechas analizadas.

Las demás variables estudiadas no mostraron diferencias por tiempo de desplazamiento, ya fuera por el escaso número de niños encontrados al estratificar o por ausencia real de diferencias; esto se evidenció especialmente en crecimiento y desarrollo, variable en la que se perdió el $30 \%$ de la información.

Al analizar las variables de la encuesta de niños escolares por tiempo de desplazamiento, se encontraron las siguientes diferencias: a mayor tiempo de desplazamiento mayor proporción de niños con carnet de vacunación, pasando de $8,2 \%$ (5/61) en el primer semestre de 2000 a 29,7\% $(30 / 101)$ en 1996 ( $p<0,005)$; igualmente, la aplicación de 3 dosis de vacuna (demostradas con carnet de vacunación) para los biológicos que lo requieren así, fue menor a menor tiempo de desplazamiento.

En cuanto a escolaridad, a mayor tiempo de desplazamiento mayor porcentaje de niños se encontraron estudiando; mientras que el $71,4 \%$ $(40 / 56)$ de los niños cuyos padres se habían desplazado en el 2000 estudiaba en el momento de la encuesta, el 93,8\% (92/98; $p<0,0001)$ de los niños de padres desplazados en 1996, se encontraba estudiando al momento de la encuesta.

Adicionalmente, a mayor tiempo de desplazamiento los padres del niño referían mejor desempeño escolar. De los niños desplazados en el 2000 que estudiaban en el momento de la encuesta, 56,9\% (33/58) refería buen desempeño; este porcentaje ascendió a 81,9\% (77/94) en los niños desplazados en $1996(p<0,05)$. Por último, a mayor tiempo de desplazamiento menor porcentaje de niños con escolaridad tardía, pasando de 15\% (14/92) en 1996 a 30\% (13/42) para los niños cuyos padres se habían desplazado en fechas más recientes $(p<0,05)$.

El abandono escolar también cambió con el tiempo de desplazamiento. A menor tiempo de desplazamiento, mayor porcentaje de personas refería haber dejado de estudiar por causa del desplazamiento o falta de cupo; sin embargo, debido al escaso número de personas en cada uno de los estratos no se tuvo poder para encontrar diferencias estadísticas. Las variables relacionadas con salud y enfermedad como morbilidad, porcentaje de niños hospitalizados, accidentes, porcentaje de consultas, y drogas, entre otras, no mostraron ninguna diferencia por tiempo de desplazamiento.

La proporción de niños afiliados a la seguridad social fue menor a menor tiempo de desplazamiento; en el primer semestre de 2000 este porcentaje fue 14,8\% (9/61), mientras que en los niños cuyos padres se desplazaron en 1996 , este porcentaje se incrementó a 38,6\% (39/101; $\mathrm{p}<0,05)$. Un comportamiento similar se observó en el porcentaje de niños con Sisben con subsidio para atención en salud, que fue 2,5 veces mayor al comparar 1996 con el primer semestre de 2000 $(p<0,05)$.

Por último, la razón que refirieron los padres para no llevar los niños a consulta médica cuando estaban enfermos, fue en mayor porcentaje la escasez de dinero a menor tiempo de desplazamiento, pasando de $61,8 \%(34 / 55)$ en el primer semestre de 2000 a 43,5\% (37/87) en 1996 $(p<0,05)$. Igualmente, a menor tiempo de desplazamiento fue menor el porcentaje de personas que refirieron no considerar necesaria la asistencia a crecimiento y desarrollo, chequeo médico o salud del escolar, pasando de 10\% (6/ 53) en el segundo semestre de 2000 a 23,7\% (23/ 92) para las personas que se desplazaron en 1996. Las demás variables analizadas como nutrición, trabajo, recreación, asistencia a programas de salud del escolar y alimentación suplementaria, no mostraron diferencias por tiempo de desplazamiento o no tuvieron suficiente poder para encontrar diferencias al estratificar.

Al analizar los datos sobre adolescentes por tiempo de desplazamiento se encontraron las 
siguientes diferencias: se observó una menor proporción de adolescentes afilados a algún sistema de seguridad social en salud (10,2\% (5/ 49) en el 2000 , comparado con el $37,8 \%(31 / 82)$ en 1996; $p=0,0006$ ); el tipo de afiliación no pudo ser analizada debido al pequeño número de sujetos en cada uno de los estratos.

Igualmente, se encontró diferencia en la proporción de personas afiliadas al Sisben con subsidio para atención en salud, siendo inferior en el 2000 (16,3\%; 8/49) al comparar con 1996 (37,8\% (31/ $82) ; p=0,009)$. Debe recordarse que todos los estratos estudiados mostraron el carnet de afiliación a salud o Sisben en más de $97 \%$ de las ocasiones.

A mayor tiempo de desplazamiento mayor proporción de adolescentes iniciaron el consumo de alcohol a edades más tempranas (entre 11 y 13 años; $p=0,003$ ). Las demás variables analizadas no mostraron diferencias por tiempo de desplazamiento, incluyendo el estado nutricional; sin embargo, debe anotarse que este grupo de edad fue el que se encontró en menor proporción en la composición de los hogares.

Analizada la encuesta para adultos por tiempo de desplazamiento se encontraron las siguientes diferencias: el promedio de cigarrillos que consumían por día las personas desplazadas fue mayor a menor tiempo de desplazamiento $(p<0,05)$. Igualmente, se observó una mayor proporción de número de tragos consumidos en cada ocasión en las personas cuyo desplazamiento fue reciente $(p<0,05)$. Si bien no se observó diferencia en la proporción de personas con enfermedad crónica, la suspensión del tratamiento para estas enfermedades por falta de recurso económico, fue mayor en años recientes de desplazamiento $(p=0,08)$, mientras que para las personas con desplazamiento más tardío lo suspendieron en mayor porcentaje por falta de seguimiento médico $(\mathrm{p}=0,08)$.

Por último, a mayor tiempo de desplazamiento se observó una mayor proporción de personas con sobrepeso y obesidad entre los 35 y 54 años, mientras que en los desplazamientos recientes la proporción fue mayor en personas de 18 a 34 años ( $p=0,05$ y 0,07 , receptivamente). Las demás variables analizadas en adultos no mostraron diferencia por tiempo de desplazamiento.

\section{Discusión}

Diversas instituciones como el Ministerio del Interior, CODHES, las Naciones Unidas y la Red de Solidaridad, entre otras, consideran que el desplazamiento interno, particularmente el desplazamiento masivo, viene en incremento en los últimos años $(1,2)$. Los hallazgos de este estudio confirman estas afirmaciones, pues se observó incremento en la tendencia global del desplazamiento al igual que en algunos departamentos y un incremento 2 veces mayor en el desplazamiento masivo al comparar los últimos años contra el periodo 1990 a 1996. Es necesario realizar estudios en otras regiones del país para poder conocer la tendencia del país.

La población desplazada es altamente vulnerable y ha sido objeto del interés de múltiples actores. Sin embargo, la población estudiada -buen porcentaje de la cual lleva viviendo varios años en el barrio- presenta deterioro severo en las condiciones socioeconómicas, disgregación familiar considerable, pésimas condiciones de saneamiento básico ambiental, alta prevalencia de enfermedades trazadoras en los diferentes grupos de edad, carencia de apoyo, falta de afiliación a seguridad social, poca cobertura y escaso acceso a los servicios de salud, entre muchos otros factores, los cuales pueden actuar sinérgicamente y afecta la salud física y mental de la población.

A pesar de los esfuerzos del gobierno, ONG y diversas redes sociales y privadas, sólo un poco más de la tercera parte de las personas desplazadas entrevistadas contó con apoyo de alimentos, dinero o atención en salud en el momento de llegar a la ciudad receptora y en este caso, el $70 \%$ de este soporte fue brindado por familiares y redes comunitarias dentro del barrio de asentamiento. Igualmente, las entidades que trabajan con esta problemática reconocen que existe dificultad para identificar tempranamente a las personas desplazadas por la violencia, impidiendo que puedan ser objeto de una intervención oportuna. 
Un fenómeno que no ha sido entendido completamente es la dinámica poblacional de las personas desplazadas por el conflicto armado interno; en este estudio se determinó la dinámica de la cohorte retrospectivamente y aunque se pudo establecer que un porcentaje de personas se desplazó luego de llegar a la ciudad receptora, no fue posible conocer completamente el movimiento de la cohorte prospectivamente, es decir, luego del ingreso a la ciudad receptora. En resumen, se observó un porcentaje de personas que se encuentra en movilidad a lo largo del tiempo, lo que plantea un reto a la oportunidad y eficiencia de los sistemas de vigilancia gubernamentales, para que puedan responder adecuadamente a las necesidades de la población desplazada, indistintamente del sitio donde llegue y de sus nuevos desplazamientos; deben estar lo suficientemente articulado entre los diferentes sectores y niveles que lo conforman y su información debe fluir al nivel central con tal dinamismo, que permitan una adecuada atención de la población.

Llama la atención el porcentaje superior del desplazamiento familiar, cifra que fue estable a lo largo de los 15 años de los que se tuvo información en el estudio, porque consideramos que son precisamente estas personas o aquéllas que se desplazan unipersonalmente, las más difíciles de detectar oportunamente por las redes privadas o gubernamentales y que deben ser rápidamente ubicadas para garantizar su intervención oportuna y retorno al sitio de origen.

Uno de los hallazgos más preocupantes fue la violencia a la que fueron y están sometidas las personas encuestadas y la disgregación familiar encontrada. El panorama de exposición a la violencia no es mucho más alentador: $80 \%$ de las personas encuestadas refirieron haber vivido experiencias violentas como tortura, asesinato, secuestro o desaparición de familiares, amigos o conocidos, con un porcentaje significativamente mayor para las personas desplazadas en los años recientes; de igual forma, los asesinatos aumentaron 3 veces, las desapariciones 6 veces y las amenazas directas a la población 8,5 veces, en un periodo de tiempo de cuatro años y como se mencionó con anterioridad, se observó un aumento en el desplazamiento masivo de personas. Sólo un pequeño porcentaje de los hogares entrevistados permanecieron sin variación después del desplazamiento; en promedio, se encontraron tres familiares ausentes por diversas causas por hogar entrevistado, la mayoría de ellos en edades económicamente productivas. Adicionalmente, se encontraban ausentes de sus hogares el $5 \%$ de los padres, el $2 \%$ de las madres y casi en el $4 \%$ de los hogares faltaban ambos padres.

Estas condiciones pueden limitar la capacidad adquisitiva de la familia, como se ha observado en diferentes estudios $(3,11,12)$, y pueden producir un incremento en el porcentaje de niños que abandonan el estudio para trabajar o que laboran más de 45 horas a la semana (condiciones observadas en este estudio), en un escenario que no está muy bien reglamentado y supervisado y, por tanto, no ofrece suficientes garantías para asegurar al niño trabajador el cumplimiento de sus derechos fundamentales o un futuro digno $y$ productivo.

Debe recordarse igualmente, que aunque por desaparición o asesinato fueron afectadas principalmente personas en edades económicamente productivas, pero que aun antes de los 4 años de edad se presentaron estos eventos y que no solo hubo exposición a la violencia en el lugar de origen de las personas desplazadas, sino que luego de llegar a la ciudad receptora, el $4 \%$ de las personas debió desplazarse nuevamente por amenazas directas y fue el asesinato la causa del $80 \%$ de las muertes reportadas por la comunidad en adolescentes y adultos (incluyendo dos decapitaciones), en los tres meses durante los cuales se realizó el trabajo de campo de este estudio.

Son muchos los autores que reconocen la fuerte asociación de la violencia como generadora de violencia y la necesidad de realizar intervenciones lúdicas dirigidas para lograr la resolución adecuada de los problemas generados por la violencia (13-15). Sin embargo, en la población estudiada la asistencia de niños y adolescentes a actividades de recreación dirigidas no fue muy baja y fue menor a menor edad de la persona 
entrevistada. Por tanto, es de esperarse que las condiciones de violencia pasadas y actuales tengan un profundo impacto negativo en la salud mental de niños y adultos y perpetúen este comportamiento en los años venideros en la población encuestada.

Las precarias condiciones de vida de la población desplazada pueden, al menos en parte, explicar la alta prevalencia de enfermedad encontrada en todos los grupos de edad: sólo el $7 \%$ de los niños menores de 5 años se encontraron completamente sanos en los 15 días anteriores a la encuesta y aunque este porcentaje fue mayor a medida que aumentó la edad de la persona entrevistada, alcanzó cifras inusualmente bajas para cualquier población.

De igual forma, esto explicaría la proporción extremamente alta de niños y adultos con sintomatología respiratoria ( $80 \%$ en menores de 5 años, mientras que en la consulta externa de Colombia entre 1989 y 1996 este valor no superó el $17 \%)(16)$, así como de diarrea (30\% en menores de 5 años, comparado con un porcentaje sobre las consultas del país que osciló en estos mismos años entre 9 y $10 \%$ en menores de 5 años) y piodermitis (32\% en menores de 5 años, comparado con $6 \%$ de las consultas en este mismo grupo de edad). Esta prevalencia también es superior a la encontrada en el Estudio de Salud Sexual y Reproductiva (17), donde la población de niños menores de 5 años con diarrea en los 15 días anteriores a la realización de la encuesta fue de $14 \%$ y con IRA de $13 \%$.

Este panorama no sería tan preocupante si la población tuviera buen acceso y cobertura de los servicios de salud; el porcentaje más alto de afiliación al Sistema de Seguridad Social en Salud se encontró en los adultos (50\%), cifra sensiblemente menor a la encontrada en la encuesta de salud sexual y reproductiva, donde el porcentaje de personas sin afiliación a seguridad social fue de $41,5 \%$.

El acceso de la población a los programas de promoción y prevención es bajo: las coberturas de vacunación encontradas en menores de 5 años son ineficaces para evitar epidemias o disminuir la incidencia de enfermedad y estaban $20 \%$ por debajo del estimado nacional o departamental para ese año en todos los biológicos, excepto BCG; estos valores sólo fueron obtenidos en niños mayores de 2 años. Igualmente, solo un pequeño porcentaje de niños menores de 5 años y escolares asistían a control de crecimiento y desarrollo, perdiéndose la oportunidad de detectar e intervenir oportunamente alteraciones del desarrollo, aprendizaje y estado de salud de los niños desplazados. Esto puede explicar porqué el $57 \%$ de la mortalidad en niños reportada por la comunidad durante el estudio era prevenible. Otros programas como la detección de cáncer de cérvix y seno y el manejo de enfermedades crónicas, entre otros, mostraron un comportamiento similar.

El estudio plantea la necesidad de introducir en la atención de la población desplazada programas efectivos de promoción y prevención que contengan: enfermedades trazadoras de la infancia; enfermedades crónicas; vacunación; control de crecimiento y desarrollo; nutrición en menores de 5 años, escolares, adolescentes y adultos; control del embarazo, planificación familiar y prevención de enfermedades de transmisión sexual; promoción de la lactancia materna; rehabilitación de discapacitados; manejo de la violencia e intervenciones lúdicas dirigidas, que permitan la resolución adecuada de conflictos; prevención del tabaquismo, drogadicción y alcoholismo, y detección precoz del cáncer de seno y cérvix.

Considerando la baja afiliación a la seguridad social, la dificultad de acceso geográfico, la ausencia de puestos de salud y hospitales dentro del barrio y las condiciones económicas de las personas, estos programas deberían estar a cargo de promotores de salud (apoyados por líderes comunitarios) quienes, a su vez, dependerían de un grupo operativo de vigilancia en salud pública, que se articularía y sería complementado técnicamente con la Dirección Municipal de Salud, formando una red con una característica fundamental: conductos de remisión fortalecidos, rápidos, eficientes y eficaces, que garanticen la atención de las personas que así lo requieran.

La Dirección Municipal de Salud se articularía con la alcaldía y otros sectores del gobierno (Hacienda, Planeación, Instituto Nacional de Vivienda de 
Interés Social y Reforma Urbana, Bienestar Familiar, entre otros), instituciones privadas, iglesia, organizaciones internacionales y ONG. La acción coordinada y conjunta de estas instituciones y la conformación de equipos en íntimo contacto con la comunidad garantizarían un mayor impacto de las acciones, la priorización y racionalización de los recursos, evitaría la duplicidad de esfuerzos y enfocaría la atención en las necesidades reales, sentidas y percibidas de la comunidad desplazada.

Permanece como un interrogante porqué no se encontraron otras enfermedades infecciosas, especialmente las transmitidas por vectores, cuando parte de la población desplazada proviene de zonas con alta prevalencia para estas entidades. El cuestionario no recogió información sobre las ciudades donde la población estuvo transitoriamente, ni preguntó sobre tratamientos recibidos en las fases de urgencia o emergencia. Consideramos que estas enfermedades deben jugar un papel importante en las dos últimas fases nombradas y cuando la población en fase de transición se ubique en una región con alta endemicidad para ellas.

Llama la atención el porcentaje importante de "lesiones en pene o cerca de vagina" que refiere la población adolescente y adulta. No fue posible saber si estas lesiones fueron debidas a enfermedades de transmisión sexual, violencia, trauma o alguna otra causa. De todos modos, bajo las condiciones de acceso e impacto de los programas de promoción y prevención, cualquiera de estos eventos puede tener un alto impacto social, económico y en salud pública.

Un porcentaje bajo de niños menores de 5 años y escolares presentaron sospecha de desnutrición; sin embargo, el peso adecuado para edad en una única valoración no necesariamente significa nutrición adecuada y, por el contrario, el porcentaje de niños con talla baja para la edad fue aproximadamente $25 \%$ en menores de 5 años y $13 \%$ en escolares, lo cual muestra que hay un problema crónico de nutrición en la población encuestada. Esta cifra es mayor a la encontrada en el 2000 en Colombia (17), donde sólo 15\% de los menores de 5 años tenía baja talla para la edad.
La proporción de adolescentes clasificados en estado de "desnutrición" fue muy alta. Por esta razón, se decidió analizar la población diferenciando por edad y género, aumentando el punto de corte a los mayores valores encontrados en la bibliografía (10); a pesar de esto, este porcentaje continuó siendo alto. Por tanto, creemos que es importante estudiar otros conglomerados para corroborar este hallazgo e incluir este grupo de edad en los programas de apoyo nutricional.

No se esperaba encontrar en una población con estas condiciones socioeconómicas personas obesas o con obesidad severa; sin embargo, el $15 \%$ de los adultos fueron clasificados en este estado por IMC. Resultados similares han sido observados con anterioridad en población general, haciendo que la OPS considere en la actualidad la obesidad en personas de escasos recursos económicos, como un problema de salud pública emergente. Basados en estos resultados, es importante que los programas de nutrición incluyan todos los grupos de edad, haciendo énfasis en la educación y buena utilización de los alimentos disponibles, teniendo en cuenta las condiciones socioeconómicas de la población.

El abandono escolar fue mayor a menor tiempo de desplazamiento y a mayor edad de la persona encuestada, alcanzando valores superiores a los obtenidos en otros estudios realizados en Colombia $(17,18)$, donde se estimó que la asistencia escolar fue de $95 \%$ en niños de 7 a 11 años y de $74 \%$ en niños entre 12 y 17 años. La principal razón para el abandono escolar fue la necesidad de trabajar para apoyar económicamente la familia y en fechas recientes de desplazamiento, además, la movilización de sus lugares de origen.

De igual forma, el desempeño escolar fue más bajo a menor tiempo de desplazamiento, lo que podría ser el reflejo del impacto sufrido por la violencia y los cambios de vida. Estos hallazgos plantean la necesidad de mejorar la cobertura y oportunidad de la educación en niños y adolescentes y la necesidad de implementar soluciones de fondo que les permita disfrutar del derecho a la educación y de actividades propias y necesarias para su desarrollo y competitividad futura. 
La escala de Zung para depresión mostró que el $23 \%$ de la población posiblemente tenía algún grado de depresión clínica. Es interesante destacar que esta prevalencia no es muy diferente a la encontrada en los estudios de salud mental realizados en Colombia (1987, 1993 y 1997), donde los valores hallados fueron $25,6,25,1$ y $19,6 \%$, respectivamente, a pesar de tratarse de investigaciones en población general (19). Es reconocido el papel protector que la familia desempeña en la salud mental (20-25); sin embargo, en la población estudiada un porcentaje importante de familias se encuentran desintegradas. Beristain menciona la inhibición de la comunicación, la desvinculación de procesos organizativos, el aislamiento social, el cuestionamiento de valores y desconfianza comunitaria como algunos efectos sociales del miedo ante el desplazamiento forzado (21). Estos hallazgos apoyan la necesidad de implementar intervenciones psicosociales dirigidas por personal capacitado para disminuir el impacto del desplazamiento forzado.

La situación no es muy diferente en otros aspectos relacionados con salud en población desplazada: las condiciones básicas ambientales son precarias; casi la totalidad de las personas se encontraron en hacinamiento y tuvieron exposición a contaminantes ambientales de todo tipo, desde contaminación del aire por cocinas mal ubicadas en las viviendas, hasta lixiviados y mal manejo de desechos y basuras.

Entre las limitaciones del estudio pueden mencionarse las siguientes: 1) para participar en la encuesta se seleccionaron con mayor frecuencia adultos y adolescentes del género femenino (10 y $5 \%$, respectivamente); $p<0.05$ ), lo que pudo ser ocasionado por la mayor facilidad para encontrar en la residencia a las mujeres o porque, por razones de seguridad, los adolescentes y adultos hombres fueron reportados como no residentes del hogar en el momento de la encuesta. Este sesgo pudo moverse en ambos sentidos; sin embargo, la prevalencia de la mayoría de los eventos en los que se esperaba encontrar diferencia por género, mostró suficiente poder estadístico para sustentar las conclusiones. 2) La población desplazada rechazó contestar algunas preguntas de particular sensibilidad, especial-mente aquellas relacionadas con violencia y los actores del conflicto, sobre todo en desplazamientos recientes, pero en ningún caso el rechazo fue superior al $20 \%$. Esto pudo afectar los resultados del estudio y ocasionar una subestimación del efecto observado. 3) Es indudable que para obtener una adecuada validez externa de este estudio, es necesario incluir otros sitios de análisis que sean seleccionados aleatoriamente de la totalidad de conglomerados de población desplazada en fase de transición. 4) Por último, algunos eventos se presentaron con menor frecuencia de lo estimado en el tamaño muestral, lo que pudo llevar a la ausencia de poder para determinar eventos de interés en población desplazada, particularmente al estratificar por tiempo de desplazamiento.

A pesar de estas limitaciones, teniendo en cuenta los hallazgos del estudio y el número importante de población afectada por el conflicto armado, el cual se presenta en más del $50 \%$ de los municipios del país, no es posible permanecer sin realizar intervenciones adecuadas y oportunas, que arrojen una luz de esperanza para esta población y un camino diferente para el país.

Consideramos esencial instaurar un sistema de vigilancia para la población desplazada que favorezca la detección oportuna y que pueda brindar apoyo a las familias una vez llegan al sitio receptor, lo cual permitiría realizar intervenciones en salud que disminuyan el impacto negativo que ocasiona el desplazamiento.

El sistema de vigilancia debe tener como base fundamental los líderes comunitarios, porque se ha descrito en múltiples ocasiones el temor de esta población a ser identificada y a pesar de que en este estudio la proporción de rechazo a participar de la encuesta fue inferior al $3 \%$, consideramos que este porcentaje debió ser mayor en desplazamientos recientes, porque eran estas personas quienes fueron amenazadas poco tiempo antes de ser entrevistadas y podían ser en mayor porcentaje objeto de discriminación al llegar a la ciudad receptora. De igual forma, el rechazo a contestar preguntas de extrema importancia en la caracterización de la población 
desplazada -particularmente aquéllas relacionadas con violencia- fue mayor en desplazamientos recientes y se encontró que a menor tiempo de desplazamiento, mayor porcentaje de personas vivían en casas prestadas ubicadas de forma dispersa en todos los sectores del barrio.

Todos estos factores permiten entender la dificultad que puede existir para detectar oportunamente a las personas desplazadas; por tanto, el éxito del sistema de vigilancia depende, en primera instancia, de contar con personas que puedan detectar fácilmente el movimiento de la población en un sector y que, además, brinden suficiente confiabilidad a las personas desplazadas, como serían los líderes comunitarios.

Considerando que el estudio mostró que la intención de retorno voluntario al lugar de origen es mayor para las personas que se han desplazado recientemente, el sistema de vigilancia sería esencial para favorecer el regreso de las familias a los sitios de procedencia, lo que impediría el aumento de los cinturones de miseria en ciudades grandes e intermedias.

La introducción de este sistema de vigilancia permitiría aunar esfuerzos de las diferentes instituciones que operan simultáneamente en los sitios afectados por el desplazamiento interno, optimizando la utilización de recursos -la mayoría de las veces escasos para la mayoría de las instituciones- pero impactando positivamente la población en sus necesidades, especialmente en quienes tienen poco tiempo de desplazamiento, cuyas condiciones psicosociales son más críticas, como se observó en este estudio.

Como se dijo con anterioridad, se encontró en la población estudiada marcada exposición a la violencia antes y después del ingreso a la ciudad receptora, ruptura de las redes sociales, disgregación familiar, deficientes condiciones socioeconómicas, bajo grado de escolaridad, consumo de drogas y alcohol y pocas oportunidades de competencia en el mercado laboral, entre otros factores, que son reconocidos a nivel internacional como terreno propicio para generar violencia intrafamiliar. Por tanto, consideramos que este factor de riesgo debe ser objeto de medición, evaluación y seguimiento en los estudios posteriores.

Este estudio confirma que el problema del desplazamiento interno es una situación compleja que requiere la asignación de recursos económicos, la optimización de los mismos y el esfuerzo conjunto de varios sectores y organizaciones para impactar positivamente la salud, entendida ésta como el bienestar físico, mental y social de la población. Para lograr este objetivo, es necesario instaurar un sistema de vigilancia con base en líderes comunitarios, que pueda identificar oportunamente los movimientos de población y los riesgos y que permita la implementación de programas de promoción y prevención, incluyendo intervenciones lúdicas realizadas por personal capacitado para la resolución de conflictos y manejo de la violencia social e intrafamiliar.

Se identificaron problemas de salud pública importantes: alta prevalencia de enfermedades transmisibles; en adultos, es posible que la obesidad sea un problema emergente y la desnutrición es motivo de preocupación en niños y adolescentes. Esto puede ser el reflejo del profundo impacto socioeconómico, ambiental y de acceso a bienes y servicios del Estado, que el desplazamiento forzado ocasiona en la población. Para disminuir este impacto, es necesario entre otras cosas, garantizar el retorno voluntario, mejorar la cobertura y oportunidad de la educación en niños y adolescentes e implementar soluciones de fondo que aumenten la competitividad futura y la realización de actividades propias y necesarias para el desarrollo de la comunidad. Estos planteamientos requieren un escenario bien reglamentado y supervisado, que asegure el cumplimiento de los derechos fundamentales. Por último, es necesario realizar otros estudios en diferentes conglomerados del país, para validar los hallazgos de este estudio.

\section{Agradecimientos}

A Tania Camacho, por su colaboración expedita y desinteresada en todos los momentos apremiantes. A Jaime Ortiz, por sus sugerencias 
para investigar los factores de riesgo ambientales. Al comité editorial de Biomédica por los invaluables aportes para el desarrollo de este documento.

A los encuestadores, quienes con su compromiso y persistencia con el trabajo hicieron posible el cumplimiento de esta labor y a los digitadores, quienes se esforzaron por cumplir a cabalidad con su trabajo, a pesar del limitado tiempo disponible.

Agradecemos muy especialmente a los habitantes del barrio Nelson Mandela de Cartagena, por participar en el estudio, por admitirnos en sus hogares y contarnos sus historias, la mayoría de ellas con recuerdos vívidos muy dolorosos.

\section{Referencias}

1. Ministerio del Interior, Red de Solidaridad Social, Departamento Nacional de Planeación. Plan de acción para la prevención y atención del desplazamiento forzado. Documento CONPES 3057 Bogotá: Ministerio del Interior; 1999.

2. Consultoría para el Desplazamiento Forzado, Codhes, Unicef. Un país que huye. Desplazamiento y violencia en una nación fragmentada. Bogotá: Codhes; 1999.

3. Alvarez M, Arias V, et al. Raíces sin tierra. Atención e impacto del desplazamiento forzoso. Bogotá: Procuraduría General de la Nación, Ministerio de Salud; Bogotá; 1999.

4. Morales M, Torres LS. Principales problemas de salud en los desplazados por la violencia, Pavarandó y Turbo, 1998. Medellín: Universidad de Antioquia, Facultad Nacional de Salud Pública; Programa de Urgencias, Emergencias y Desastres DSSA; 1998.

5. Esteve $\mathbf{J}$ et al. Descriptive epidemiology. Scientific Publications No. 128. Lyon: IARC; 1994.

6. Rothman KJ, Greenland S. Modern epidemiology. Second edition. Filadelfia: Lippincott Raven Publishers; 1998.

7. Malilay $\boldsymbol{J}$ et al. Método modificado de muestreo por conglomerados para la evaluación rápida de necesidades después de un desastre. Rev Panam Salud Pública 1997;2:7-12.

8. González M et al. Epidemiología de los trastornos mentales en Bogotá. Bogotá: Instituto Colombiano del Sistema Nervioso, Clínica Montserrat; 1978.

9. American Psychiatric Association. DSM-IV draft criteria. Washington, D.C.: American Psychiatric Association; 1993.
10. Rosner B et al. Percentils for body mass index in U.S. Children 5 to 17 years age. J Paedriatric 1998;132:211 -22 .

11. Franco S. Violencia y salud en Colombia. En: Ministerio de Salud y Corporación Salud y Desarrollo, editores. Memorias, El sector salud frente a la violencia en Colombia. Bogotá: Ministerio de Salud y Corporación Salud y Desarrollo; 1997.

12. Reyes A. Geografía de la guerra. El Tiempo, Lecturas Dominicales, Santafé de Bogotá, 1999.

13. Bello M, Mantilla L et al. Relatos de la violencia. Impactos del desplazamiento forzado en la niñez y la juventud. Bogotá: Editorial Unibiblos; 2000.

14. Farrington DP. The Twelfth Jack Tizard Lecture. The development of offending antisocial behavior from childhood: key findings from Cambridge study in delincuent development. J Child Psychology and Psychiatry 1995;360:929-64.

15. Castaño BL. Violencia sociopolítica en Colombia. Repercusión en la salud mental de las víctimas. Bogotá: Corporación Avre; 1994.

16. Ministerio de Salud. SIS 12, 1989-1996.

17. Profamilia. Salud sexual y reproductiva en Colombia. Encuesta Nacional de Demografía y Salud, 2000. Primera edición. Bogotá: Printex Impresores Ltda.; 2000.

18. Departamento Administrativo Nacional de Estadísticas (DANE). Encuesta nacional. Bogotá: Departamento Administrativo Nacional de Estadísticas (DANE); 1999.

19. Levav I. Salud mental para todos en América Latina y el Caribe. Bases epidemiológicas para la acción. En: Ministerio de Salud, editores. Estudio nacional de salud mental y consumo de sustancias psicoativas. Santafé de Bogotá: Ministerio de Salud; 1993.

20. Committee for Refugees. La crisis silenciosa de Colombia. En: Ministerio de Salud, Organización Panamericana de la Salud y Corporación Salud y Desarrollo, editores. El sector salud frente al desplazamiento por la violencia en Colombia. Santafé de Bogotá: Ministerio de Salud, Organización Panamericana de la Salud y Corporación Salud y Desarrollo; 1998.

21. Beristan C M. Reconstruir el tejido social. Un enfoque crítico de la ayuda humanitaria. Barcelona: Icaria Editorial; 1999.

22. Martín-Baró I. Psicología social de la guerra. En: Beristan CM, editor. Reconstruir el tejido social. Un enfoque crítico de la ayuda humanitaria. Barcelona: Icaria Editorial; 1999.

23. Sveass N. Implicaciones psicosociales de la impunidad. En: Beristan CM, editor. Reconstruir el tejido social. Un 
enfoque crítico de la ayuda humanitaria. Barcelona: Icaria Editorial, Barcelona; 1999.

24. Summerfield D. El impacto de la guerra y de la atrocidad en las poblaciones civiles. Principios básicos para intervenciones de ONG y una crítica de los proyectos de traumatismo psicosocial. En: Castaño $\mathrm{BL}$, Jaramillo LE, editores. Violencia política y trabajo psicosocial. Santafé de Bogotá: Corporación Avre; 1998.

25. Summerfield $\mathbf{D}$. The impact of war and atrocity on civilian populations: and overview of major themes. En: Beristan CM, editor. Reconstruir el tejido social. Un enfoque crítico de la ayuda humanitaria. Barcelona: Icaria Editorial; 1999. 